\title{
Google Scholar Citation metrics of Pakistani LIS scholars: An overview
}

Muhammad Yousuf Ali, Faculty of Health Science, Library, Aga Khan University, Karachi, Pakistan Joanna Richardson, Department of Library and Learning Services, Griffith University, Meadowbrook, Australia

\begin{abstract}
Purpose - The purpose of this study is to analyze the use of Google Scholar Citations' profiling platform by library and information science (LIS) scholars in Pakistan.

Design/methodology/approach -Purposive sampling was used to collect Google Scholar Citations profiles between 15 November 2017 and 31 January 2018. Resultant data were analyzed in SPSS Version 21.

Findings - In terms of demographical data, study results were consistent with previous studies of Pakistani LIS scholars. There were strong correlations between Google Scholar Citations metrics (publications, citations, h-index, and i10-index). The results indicate that, compared with a 2011 survey of LIS academics in Pakistan, the overall uptake for this cohort remains relatively low. This cohort is not maximizing the opportunity provided by this specific online profiling system to increase research visibility.
\end{abstract}

Research limitations/implications - As the study was limited to those Pakistani LIS scholars who already had a profile on ResearchGate, it would be useful to broaden the research to encompass all Pakistani LIS scholars.

Practical implications - The role of the librarian as an adviser in scholarly communication and impact can be extended to support scholars in the adoption of new online platforms for scholarly communication and visibility.

Originality/value - There have been no published research studies on Google Scholar Citations metrics in the context of Pakistani LIS scholars as a whole.

Keywords Research impact; LIS researcher; Researcher profile; Scholarly profile; Academic social networking; Altmetrics

Paper Type Research paper

\section{Introduction}

Bibliographic data is an important element in any research evaluation process. Its use in performance evaluation is in fact decades old, as evidenced, for example, by the work of Moed et al. (1984). In recent years, there has been a shift from focusing principally on the research performance of individuals to that of whole-of-institution (Mingers and Meyer, 2017). Gingras (2016) has also noted that the evaluation of research performance is now common across all levels of universities.

In the current higher education research environment, there has been a growing interest in creating more effective evaluation tools to measure research performance. According to the Office of Economic Development (2010, p. 3), such tools help to inform decisions on research funding and lead to greater accountability. Unsurprisingly, what is clearly evolving are "new bibliometric indicators as well as new 
variants or combinations of established ones" (Wildgaard et al., 2014, p. 125). For example, the emergence of the Open Access movement along with technological advances in scholarly communication has given rise to new indicators, such as altmetrics and social media (Veletsianos, 2016; Priem et al., 2012).

In turn, this has led to the establishment of social networking websites, which target particularly the academic community. Known as Academic Social-or Scholarly-Networking Sites (ASNS), they include, but are not limited to, Academia.edu, Mendeley, ResearchGate, and Google Scholar Citations. One of the primary features of ASNS is the provision of an online profiling platform, where authors can create professional curriculum vitae. ASNS are not unique in offering this service; other major systems include ORCID, Kudos and Publons (Gasparyan et al., 2017). The degree of functionality varies among the different systems.

In Pakistan, as in other developing countries, the national body responsible for higher education, i.e. the Higher Education Commission (HEC), has promulgated goals regarding improving research outcomes. Given the potential of online profiling systems to increase researcher impact (Delgado López-Cózar et al., 2018; Martín-Martín et al., 2018; Gasparyan et al., 2017), the authors have investigated the use specifically of Google Scholar Citations' profiling platform by library and information science (LIS) scholars in Pakistan. For the purposes of this paper, the authors have used the term "scholar" to encompass LIS academics, researchers, and professionals (practitioners).

\section{Related research}

\subsection{Citation databases / indices}

Using bibliometric data as a foundation, major publishers have created large abstract and citation databases / indices to support research evaluation, e.g. Web of Science, Scopus, and, more recently, Google Scholar. Citations are important because, as Thelwall and Kousha (2017, p. 1125) observe, "Citation counts are frequently used to support research evaluations, for example to help compare the relative merits of individual researchers or research groups". They are also reported in various international ranking systems, e.g. QS World University Rankings, Times Higher Education World University Rankings, and Academic Ranking of World Universities (ARWU).

It is not the authors' intention to discuss the relative merits, or otherwise, of the use of citations as a meaningful research performance metric, as the topic has already been well covered for many years in the literature. However, a brief overview of the three major citation systems is useful to help contextualize the authors' investigation of Google Scholar Citations as an online profiling platform that uses a citation database, i.e. Google Scholar, as the foundation for its service.

Between 2006 and 2017, a number of researchers have reported on their comparative studies of Web of Science (WoS), Scopus, and Google Scholar's (GS) citation databases. Whereas Meho and Yang (2007, p. 2105) concluded that the "use of Scopus and GS, in addition to WoS, helps reveal a more accurate and comprehensive picture of the scholarly impact of authors", Falagas (2008, p. 338) reported that "For citation analysis, Scopus offers about $20 \%$ more coverage than Web of Science, whereas Google Scholar offers results of inconsistent accuracy". In a comparative study of the coverage of business and management, Mingers and Lipitakis (2010, p. 625) concurred that Google Scholar suffered from problems of data reliability, but concluded that it was more comprehensive than WoS. 
According to Bornmann et al. (2016, p. 2779), Google Scholar has been proposed as either an alternative or a supplement to WoS and Scopus, given the latters" "fundamental limitations" when applied to the humanities and social sciences. Mingers and Meyer (2017) agree with the issue of limited coverage but note that, unlike WoS and Scopus, Google Scholar lacks any normalization of data across disciplines. For their part, Kousha and Thelwall (2017, p. 763) make the important point that Google Scholar may have a key role to play in the assessment of scholarly publications in those countries and languages that are not well covered currently by either WoS or Scopus. In addition, Thelwall and Kousha (2017, pp. 1125-1126) observe that "An ongoing problem with traditional citation is that they take several years to appear in the Web of Science (WoS) and Scopus due to publishing delays. This is a major drawback for research evaluators because the most recent research seems likely to be the most relevant for an evaluation".

In their respective study of these three indexing databases, Shah et al. $(2017$, p. 10) conclude that "Reference and citation-extended databases have their strengths and weaknesses. There is no 'one size fits all' case in research". Their findings corroborate the much earlier results from two studies, in which researchers from Indiana University (Meho and Yang, 2007; Yang and Meho, 2006) reported that all three indexing databases provided different coverage for LIS faculty members.

\subsection{Online profiling platforms}

While scholars have relied until recently upon traditional citation services to provide an overview of their research impact, the advent of academic social (scholarly) networking sites has provided the potential for new insights. Williams and Woodacre (2016, p. 286) have observed:

As higher education scholars attempt to negotiate their participation in ASNSs, they are working to establish a professional online culture unique to academia. This culture and the practices used to encourage and maintain participation will continue to impact academic research and professional expectations in the future. Since academic social networks are continuously evolving, it is necessary for researchers to stay abreast of platform updates and changes in use, particularly among their scholarly peers.

Whereas citation databases have as their primary focus the publication, newer bibliographic tools such as online profiling platforms tend to focus on the author and, as such, are intended to supplement longstanding, traditional resources. Along with some elements associated with standard citation analysis, these platforms tend to offer a newer, wider range of alternative metrics, e.g. downloads and views. Depending upon the platform, authors may be able to upload a photograph as well as add bibliographic data for items which have been published but not indexed by any of the standard, indexing tools.

More recently, Gasparyan et al. (2017) have provided a useful overview of both the widely used and emerging online profiling platforms, some of which are provided as a service by an ASNS. They have concluded that "Opening an individual account and filling it with scholarly contents increase visibility of research output and boost its impact" (p. 1749).

A number of researchers have reported on their studies of the more widely used platforms. For example, Ortega and Aguillo (2014) found that Google Scholar Citations profiles contained more documents and citations and had a higher updating rate than Microsoft Academic Service (MAS). However, while the latter's profiles offered a more balanced disciplinary coverage, MAS also had a higher number of duplicated profiles. The authors concluded that "both services could be used for 
evaluation proposes only if they are applied along with other citation indices as a way to supplement that information" (p. 1149). For her part, Naude (2017, p. 22) concluded that the usage data (downloads) and alternative metrics data in Mendeley could be a useful complement to the citation data in Google Scholar Citations for determining influential authors and articles in the subject area of Information and Communication Technology for Development ICT4D), given the absence of electronic bibliometric data and citation tools.

In their extensive review of five profiling platforms, Martín-Martín et al. (2016) found that Google Scholar Citations outperformed the other four in terms of the number of user profiles created and the regularity with which these were updated. However, they also noted that ResearchGate's "usage indicators (Downloads and Views) and its social network features (communication and information sharing among users) provide a perspective that Google Scholar Citations lacks" (p. 56).

Thelwall and Kousha (2017, p. 1125) point out that, in their analysis of LIS articles published between January 2016 and March 2017, "ResearchGate found less citations than did Google Scholar but more than both Web of Science and Scopus. This held true for the dataset overall and for the six largest journals in it. ResearchGate correlated most strongly with Google Scholar citations, suggesting that ResearchGate is not predominantly tapping a fundamentally different source of data than Google Scholar".

In their study of faculty at the University of Vermont, DeSanto and Nichols (2017) reported that most respondents (78.5\%) did not use any application or tools, e.g. Google Scholar Citations or ResearchGate profile, to track metrics related to their own scholarly work. Of the $21.5 \%$ who did use such tools, no respondent was from a field within the humanities and arts. In a recent study of bibliometrics researchers, Martín-Martín et al. (2018) observed that "a high number of the analysed researchers only had a profile in Google Scholar Citations (159), or only in Google Scholar Citations and ResearchGate (142)" (p. 494).

While outlining the potential benefits of creating a scholarly online profile, researchers have expressed concern about perceived negative aspects (Jordan and Weller, 2018). Orduna-Malea et al. (2016, p. 1), for example, have referred to the creation of such profiles as "a new addictive game for researchers". Several studies have highlighted ways in which content can be manipulated in such a way as to inflate citation metrics (Karanatsiou et al., 2017; Kousha and Thelwall, 2017; Oravec, 2017; Doğan et al., 2016; Hammarfelt et al., 2016; Thelwall and Kousha, 2015; Bornmann, 2014; Delgado López-Cózar et al., 2014; Jacsó, 2012).

\subsection{Google Scholar Citations profiling feature}

Released in 2004 (Vine, 2006, p. 97), Google Scholar is a freely accessible, web-based service that indexes the metadata of scholarly literature across a range of formats and disciplines. It offers users the ability to search for the full-text (where the license permits) of scholarly outputs, and retrieve the related metadata and citation metrics. In addition to the more traditional publishing formats, coverage includes preprints, abstracts, and technical reports.

For the purposes of this paper, the authors have focused specifically on the profiling feature within "Google Scholar Citations". In 2012, Google enhanced its service to allow scholars to create their own Google Scholar "profile" by logging on through a Google account. While the software automatically 
displays metadata relevant to existing publications in its database linked to that author, a scholar now has the ability to add other publications manually. This is done by either searching the database or entering the bibliographic data by hand. Similar to other ASNS, scholars can "follow" other scholars, i.e. receive emailed updates about new articles and/or citations related to their publications.

Google Scholar provides statistics for three categories of citation metrics: citations, $\mathrm{h}$-index, and i10index. "Citations" represents the total number of citations for all publications linked to a scholar's profile. The h-index is based on Hirsch's (2005, p. 16569) definition: "the number $[h]$ of papers with citation number $\geq h$ ". The i10-index is the number of publications with at least 10 citations; this metric is unique to Google Scholar. Each scholar's profile represents these metrics in two ways: (1) a graph showing the annual number of all citations for the past 7 years, and (2) a table showing (a) the total number of citations plus current $\mathrm{h}$-index and i10-index scores, and (b) the same categories but limited to statistics for the past 5 years. This data is updated whenever the database is updated.

Not long after Google Scholar's inception, Hartman \& Bowering Mullen, (2008, p. 219) outlined the characteristics that made (and still make) it attractive to scholars:

[...] Google Scholar has also been the focus of numerous articles on citation analysis, and many researchers are interested in web visibility as a way of increasing research impact. Any tool that provides "cited by" references, and that can provide information to researchers about who is citing their work will gather many devotees, even if the algorithms are automatic, and the content searched a mixed bag.

In 2009, Beel and Gipp (p. 161) discussed the reliability of Google Scholar as a "serious information source". For their part, Ortega and Aguillo (2012, p. 2370) noted the attractiveness of that the fact that the "Google Scholar database allows direct creating and editing in a personal profile, correctly assigning your own publications and deleting duplicates and other mistakes".

Delgado López-Cózar et al. (2014) reported on the relative ease with which authors could manipulate citation counting in Google Scholar Citations, but concluded that "one cannot expect GS to develop tools to avoid fraud when this has not been accomplished by traditional citation indexes" (p. 453). Van Bevern et al. $(2015$, p. 808) initially reported that the" H-index of Google Scholar profiles [were] vulnerable to manipulation by untruthful authors". However, they $(2016$, p. 19) subsequently modified this observation by reporting that "Experiments on Google Scholar profiles of Al researchers show that the $\mathrm{H}$-index can be manipulated substantially only if one merges articles with highly dissimilar titles". While acknowledging these shortcomings, Delgado López-Cózar et al. (2018, p. 37) have concluded that Google Scholar provides "access to previously unexplored territories of knowledge which, even if only roughly, are allowing us to form a broader mental picture of academic activity".

In the following table (Table I), the authors have summarised the key attributes of Google Scholar Citations in terms of its underlying citation database (Google Scholar) and its profiling platform (Google Scholar Citations profiling feature), as identified from the authors' literature review. 
Table I. Key attributes of Google Scholar Citations

\begin{tabular}{|c|c|c|}
\hline \multicolumn{3}{|l|}{ Google Scholar } \\
\hline Attribute & Assessment & Source \\
\hline Comprehensiveness & $\begin{array}{l}\text { More comprehensive than Web of } \\
\text { Science (WoS) }\end{array}$ & $\begin{array}{l}\text { Mingers and Lipitakis, } \\
2010\end{array}$ \\
\hline Coverage & $\begin{array}{l}\text { Better in humanities and social } \\
\text { sciences than WoS and Scopus } \\
\text { Better coverage of countries and } \\
\text { languages }\end{array}$ & $\begin{array}{l}\text { Bornmann et al., } \\
\text { 2016; Gasparyan et } \\
\text { al., 2017; Mingers } \\
\text { and Meyer, } 2017 \\
\text { Kousha and Thelwall, } \\
\text { 2017; Delgado López- } \\
\text { Cózar et al., } 2018\end{array}$ \\
\hline Data normalisation & $\begin{array}{l}\text { None, unlike in the case of WoS and } \\
\text { Scopus }\end{array}$ & $\begin{array}{l}\text { Mingers and Meyer, } \\
2017\end{array}$ \\
\hline $\begin{array}{l}\text { Organized thesaurus for } \\
\text { systematising searches }\end{array}$ & None & $\begin{array}{l}\text { Gasparyan et al., } \\
2017\end{array}$ \\
\hline Data reliability & There are some issues & $\begin{array}{l}\text { Mingers and Lipitakis, } \\
\text { 2010; Delgado López- } \\
\text { Cózar et al., } 2018\end{array}$ \\
\hline Timeliness & $\begin{array}{l}\text { Citations appear more quickly than in } \\
\text { WoS or Scopus }\end{array}$ & $\begin{array}{l}\text { Thelwall and Kousha, } \\
2017\end{array}$ \\
\hline Ease of use & $\begin{array}{l}\text { No statistically significant difference } \\
\text { when compared with WoS }\end{array}$ & Kim, 2014 \\
\hline \multicolumn{3}{|l|}{ Profiling feature } \\
\hline Attribute & Assessment & Source \\
\hline Alternative metrics data & $\begin{array}{l}\text { No downloads or other alternative } \\
\text { metrics data }\end{array}$ & Naude, 2017 \\
\hline Regularity of updates & $\begin{array}{l}\text { Outperformed four other popular } \\
\text { profiling platforms }\end{array}$ & $\begin{array}{l}\text { Martín-Martín et al., } \\
2016\end{array}$ \\
\hline $\begin{array}{l}\text { Ability to edit records } \\
\text { directly }\end{array}$ & $\begin{array}{l}\text { Authors can perform this function } \\
\text { without having to contact the relevant } \\
\text { support personnel }\end{array}$ & As per website \\
\hline $\begin{array}{l}\text { Ability to add publications } \\
\text { not indexed by the } \\
\text { system, i.e. Google } \\
\text { Scholar }\end{array}$ & $\begin{array}{l}\text { Authors can add other publications } \\
\text { manually }\end{array}$ & As per website \\
\hline Author identifier & Not generated & As per website \\
\hline Personalisation & $\begin{array}{l}\text { A profile can include a photograph, } \\
\text { plus links to similar profiles of co- } \\
\text { authors }\end{array}$ & $\begin{array}{l}\text { Gasparyan et al., } \\
2017\end{array}$ \\
\hline Validation tools & $\begin{array}{l}\text { Some efforts have been made to } \\
\text { introduce these } \\
\mathrm{H} \text {-Index can be manipulated } \\
\text { significantly but only in a way that } \\
\text { would reveal the underlying } \\
\text { manipulation }\end{array}$ & $\begin{array}{l}\text { Mingers and Meyer, } \\
\text { 2017; } \\
\text { Van Bevern et al., } \\
2016\end{array}$ \\
\hline
\end{tabular}




\subsection{Use of Google Scholar Citations profiling system by Pakistani LIS scholars}

In the Pakistani context, several researchers have published recent studies of the research performance of several cohorts of Pakistani scholars based on their membership of an ASNS (Ali and Richardson, 2018; Ali and Richardson, 2016; Sheikh, 2016). In their survey of research publishing specifically by Pakistani LIS scholars, Ali and Richardson (2016) reported that only 29 of 104 respondents (27.88\%) indicated that they did not use any scholarly network. The authors of the current study (Anonymous, 2017) have reported on the altmetrics of ResearchGate profiles for 78 Pakistani LIS scholars.

With specific reference to Google Scholar, Jan and Anwar (2013) conducted a study of the publications and citations of LIS faculty members in eight Pakistani universities. Based on data collected in mid-2011, they found that only 11 (20.75\%) of the 53 members of this cohort had at least one publication that had been cited, according to Google Scholar. The objective of the study was to analyse the research performance of this cohort as one method of informing a range of outcomes: "The performance of the faculty of a school can be used as an indicator of its quality. Therefore, it is important to know the ranking of the LIS faculty to help new comers [sic] in deciding which school to join. Also the ranking will help the top administration in promotion, awarding research grants, and in selection for best teacher awards" (p. 6). They attributed the relatively low bibliometric scores to the lack of publishing in impact factor journals.

In their analysis of the relevant literature, the authors have found no study thus far of Google Scholar Citations metrics in the broader context of Pakistani LIS scholars as a whole. This study is intended to fill that gap.

\section{Research objectives}

In recent decades, there has been an increased interest in enhancing the visibility and subsequent impact of research outputs. As evidenced by the literature review, researchers are examining the potential of online profiling systems to complement the traditional citation services.

To this end, this paper reports on an analysis of the profiles of Pakistani LIS scholars who are members of Google Scholars Citations' profiling system in terms of the following metrics: publications, citations, $\mathrm{h}$ index score, and i10-index score. These metrics will be useful not only for providing insights into the visibility and research performance of this cohort but also for researchers in other countries and/or disciplines who would wish to conduct a similar study.

This study has focused on the following research questions:

RQ 1. How many Pakistani LIS scholars, identified previously in a 2017 study, have a Google Scholar Citations profile?

RQ 2. How well has this cohort performed in terms of Google Scholar Citations metrics, i.e. number of publications, citations, h-index score, and i10-index score?

RQ 3. What is the correlation (if any) among Google Scholar Citations metrics?

RQ4. What activities could LIS scholars and other stakeholders undertake to leverage the potential of Google Scholar Citations' profiling system? 


\section{Methodology}

This is an exploratory, quantitative study, based on the use of Google Scholar by Bornmann et al. (2016) for their bibliometric study within the broad area of the social sciences and humanities.

Following a method applied by the authors (Anonymous, 2017) in their study of ResearchGate, this study has used the purposive sampling technique, which selects a target group "based on a specific purpose rather than randomly" (Tashakkori and Teddlie, 2003). Originally, a sample was derived from all Pakistani library and information science professionals and academics who had a profile on ResearchGate. Of the 103 scholars who met the criteria, 78 (75.73 per cent) listed at least one publication.

The authors then manually checked the 78 profiles against Google Scholar. Metrics reported in this study were extracted from Google Scholar between 15 November 2017 and 31 January 2018.

Collected data were entered into Microsoft Excel and then analyzed in SPSS Version 21.0. Following the same methodology as Yu et al. (2016) in their study of ResearchGate, this study has used Pearson correlations.

\section{Data Analysis}

Of the 78 Pakistani LIS scholars who had a profile on ResearchGate which listed at least one publication, 45 (57.69\%) had a profile on Google Scholar.

\subsection{Demographical}

Table II shows that 38 (84.44\%) scholars were male and 7 (15.56 per cent) were female. Whereas 24 (53.33 per cent) scholars were from the public sector, 21 (46.67 per cent) were from the private sector. Of the 45 LIS profiles on Google Scholar, 13 (28.88 per cent) were of faculty members and 32 (71.12 per cent) were of LIS practitioners.

Table II. Demographics

\begin{tabular}{|c|c|c|}
\hline \multicolumn{3}{|l|}{ a. Gender } \\
\hline & Frequency & $\%$ \\
\hline Female & 7 & 15.56 \\
\hline \multirow[t]{2}{*}{ Male } & 38 & 84.44 \\
\hline & $N=45$ & 100.00 \\
\hline \multicolumn{3}{|l|}{ b. Sector affiliation } \\
\hline & Frequency & $\%$ \\
\hline Public & 24 & 53.33 \\
\hline \multirow[t]{2}{*}{ Private } & 21 & 46.67 \\
\hline & $N=45$ & 100.00 \\
\hline \multicolumn{3}{|l|}{ c. Professional status } \\
\hline & Frequency & $\%$ \\
\hline Faculty member & 13 & 28.88 \\
\hline \multirow[t]{2}{*}{ Practitioner } & 32 & 71.12 \\
\hline & $N=45$ & 100.00 \\
\hline
\end{tabular}




\subsection{Number of publications}

The 45 scholars had a total of 858 publications, with a range between 1 and 166 publications in a single profile, and with a mean $=19$. Table III shows the distribution of publications by total number per scholar. Three scholars can be considered as outliers, i.e. their total number of publications is distant from the other 42 in the sample population. These 42 scholars have less than 40 publications each but account for 93.33 per cent of the 858 publications.

Table III. Frequency distribution by number of publications per scholar

\begin{tabular}{|l|c|r|}
\hline Number of publications per scholar & Number of scholars & $\mathbf{\%}$ \\
\hline $85+$ & 3 & 6.67 \\
\hline $21-37$ & 11 & 24.44 \\
\hline $11-20$ & 8 & 17.78 \\
\hline $6-10$ & 11 & 24.44 \\
\hline $1-5$ & 12 & 26.67 \\
\hline Total & $\mathbf{4 5}$ & $\mathbf{1 0 0 . 0 0}$ \\
\hline
\end{tabular}

Just three scholars (6.67 per cent) accounted for 354 (41.26 per cent) of the total number of publications in Google Scholar for this cohort. The majority of scholars had less than 40 publications per profile, with 12 (26.67 per cent) having between 1 to 5 publications.

\subsection{Citations}

Individual scholar profiles ranged from zero to 1,805 citations. The average number of citations per publication was 5.42. Table IV shows the distribution of citations by total number per scholar.

Table IV. Frequency distribution by number of citations per scholar

\begin{tabular}{|l|c|r|}
\hline Number of citations per scholar & Number of scholars & \% \\
\hline $1,000+$ & 1 & 2.22 \\
\hline $101-999$ & 6 & 13.33 \\
\hline $81-100$ & 2 & 4.44 \\
\hline $61-80$ & 5 & 11.11 \\
\hline $41-60$ & 5 & 11.11 \\
\hline $21-40$ & 4 & 8.89 \\
\hline $11-20$ & 7 & 15.56 \\
\hline $1-10$ & 10 & 22.22 \\
\hline 0 & 5 & 11.11 \\
\hline Total & $\mathbf{4 5}$ & $\mathbf{1 0 0 . 0 0}$ \\
\hline
\end{tabular}

Of the 45 scholars, 40 (88.89 per cent) had at least one citation; 5 (11.11 per cent) had no citations, although they each had up to 7 publications. Whereas 15 scholars (or one-third) had between zero and 10 citations, 15 scholars (or one-third) had more than 60 citations. The remaining third had between 11 and 59 citations each.

\subsection{Publications and citations}


The 858 publications received 4,653 citations. The same three scholars mentioned above accounted for 3,059 citations, or 65.74 per cent.

Figure 1 shows the wide range among the profiles.

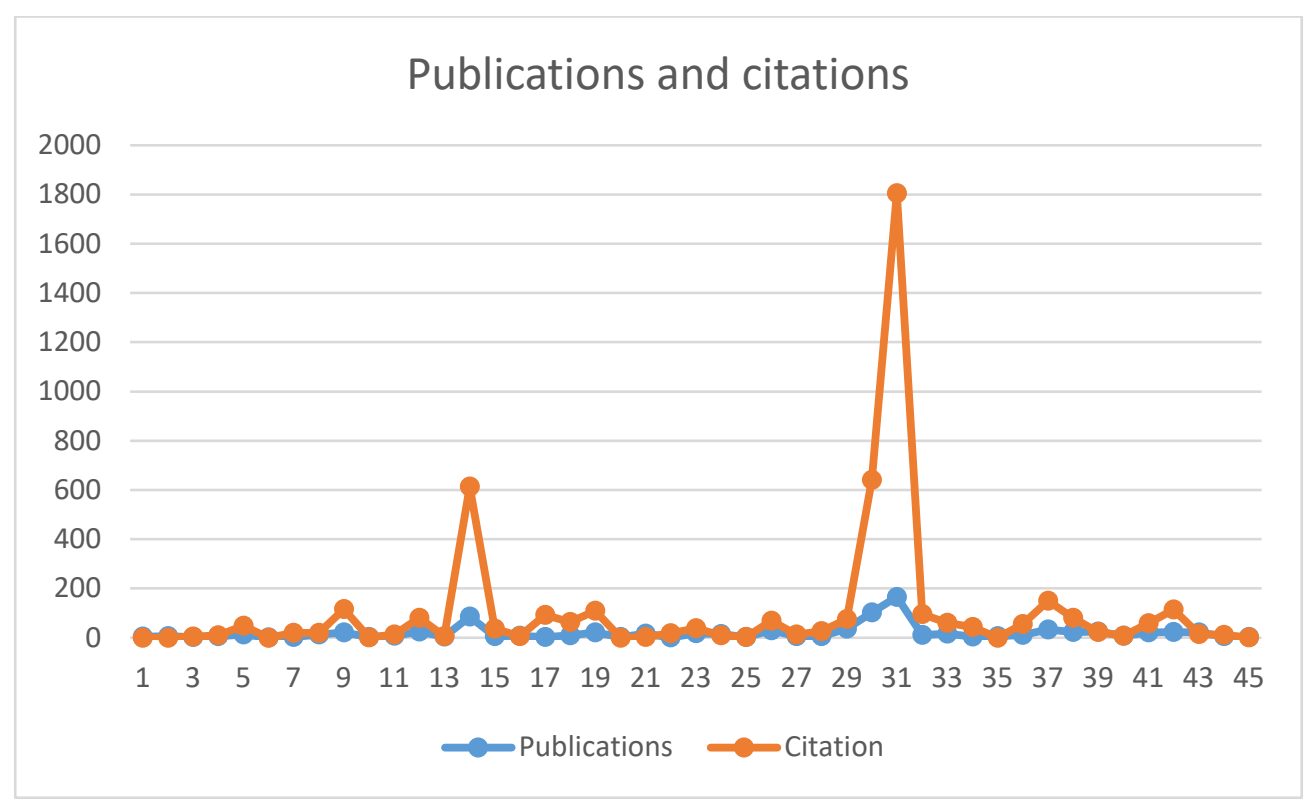

Figure 1.

Table $V$ shows the association between publications and citations in Pakistani LIS scholars' profiles. A Pearson correlation with a value of $r=0.947$ indicates that there is a strong association between the number of publications and corresponding number of citations among this cohort.

Table V: Pearson correlation between number of publications and citations

\begin{tabular}{|rl|r|r|}
\hline & & Publications & Citations \\
\hline \multirow{4}{*}{ Publications } & Pearson Correlation & 1 & $.947^{* *}$ \\
& Sig. (2-tailed) & & .000 \\
& $\mathrm{~N}$ & 45 & 45 \\
& Pearson Correlation & $.947^{* *}$ & 1 \\
Citations & Sig. (2-tailed) & .000 & \\
& $\mathrm{~N}$ & 45 & 45 \\
\hline
\end{tabular}

**. Correlation is significant at the 0.01 level (2-tailed).

\subsection{Citations and $h$-index}

Of the 45 scholars, 40 (88.89 per cent) had an h-index score. Five (11.11 per cent) had no h-index, although they each had up to seven publications. For those with an $\mathrm{H}$-index score, values ranged from 1 to 23 , with a mean $=3.78$. 


\section{h-index}

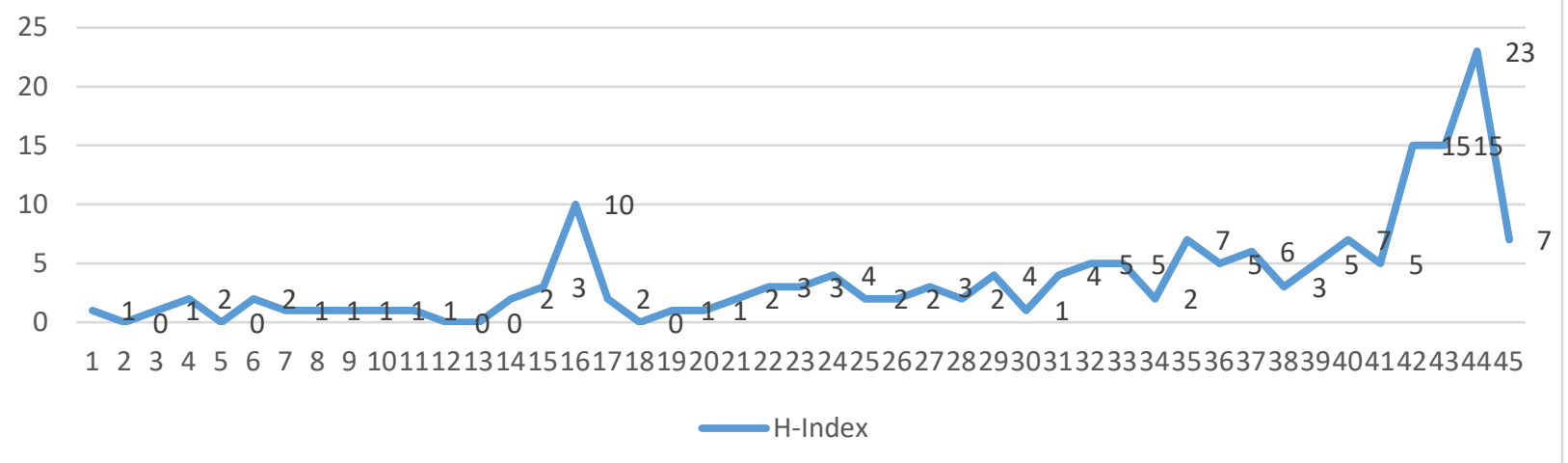

Figure. 2

For purposes of readability, the three scholars with the highest number of citations have been excluded from Figure $3(n=42)$, which shows each scholar's overall citation count and their $h$-index score.

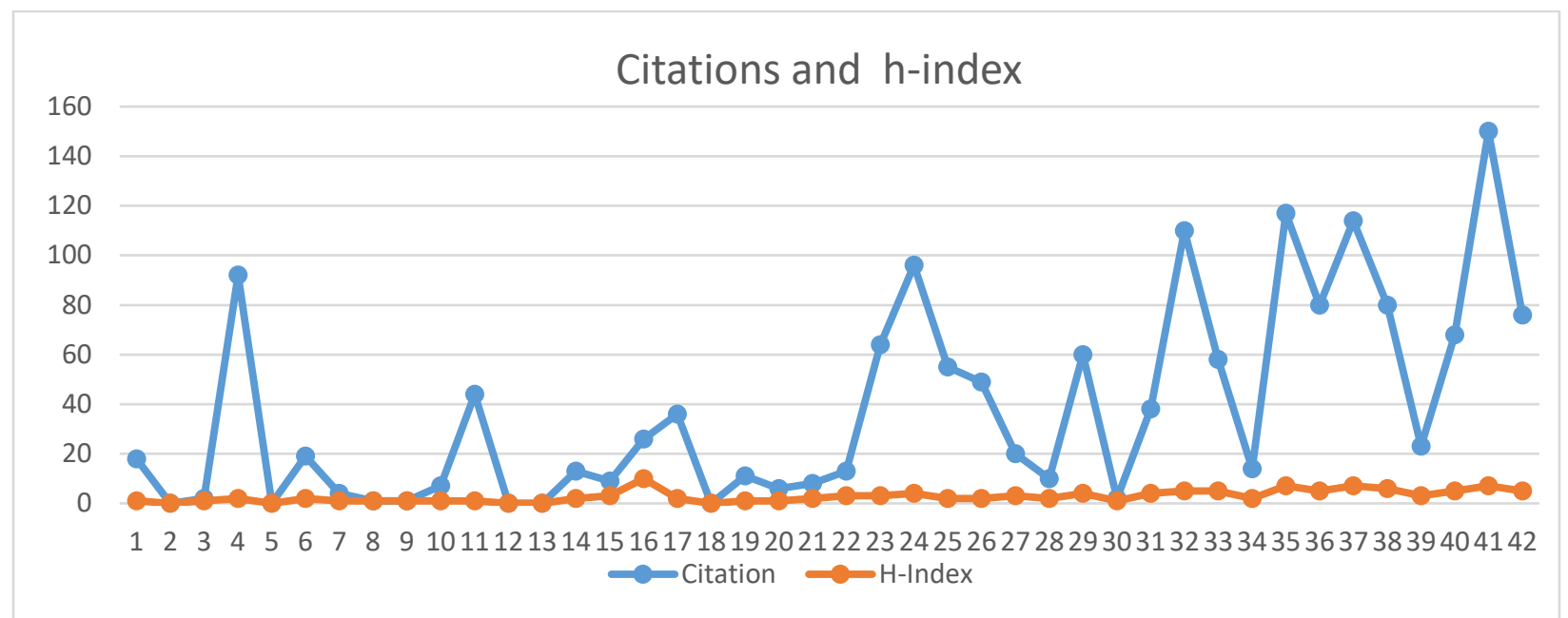

Figure 3.

Table VI shows the association between citations and h-index in the Pakistani LIS scholars' profiles. A Pearson correlation with a value of $r=0.875$ indicates that there is a strong association between the number of citations and corresponding $h$-index among this cohort.

Table VI: Pearson correlation between number of citations and corresponding $\mathrm{h}$-index

\begin{tabular}{|cc|c|c|}
\hline & & Citations & h-index \\
\hline & Pearson Correlation & 1 & $.875^{* *}$ \\
Citations & Sig. (2-tailed) & & .000 \\
& $\mathrm{~N}$ & 45 & 45
\end{tabular}




\begin{tabular}{|cc|c|c|} 
& Pearson Correlation & $.875^{* *}$ & 1 \\
H-index & Sig. (2-tailed) & .000 & \\
& $\mathrm{~N}$ & 45 & 45 \\
\hline
\end{tabular}

**. Correlation is significant at the 0.01 level (2-tailed).

\subsection{H-index and i10-index}

Out of 858 articles, 155 (18.07 per cent) had more than 10 citations. Of the 45 scholars, 26 (57.78 per cent) had an i10-index score and 19 (42.22 per cent) had no score. Scores for the i10-index metric ranged from zero to 50 , with a mean $=5.96$.

\section{h-Index \& i10-Index}

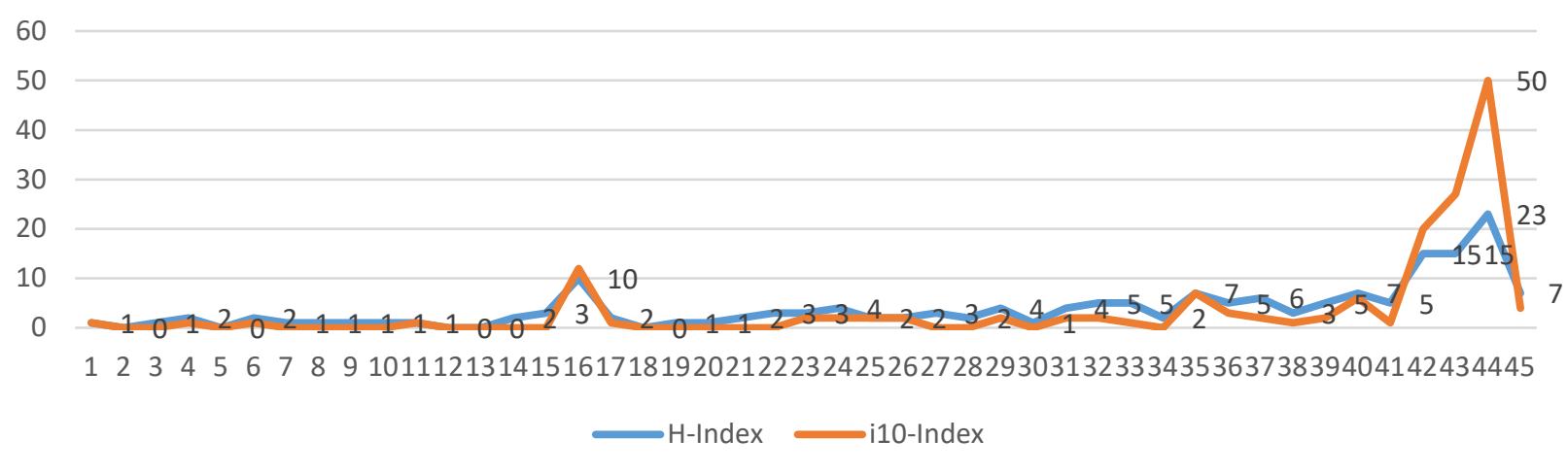

Figure 4.

Table VII shows the association between the h-index and i10-index in the Pakistani LIS scholars' profiles. A Pearson correlation with a value of $r=0.932$ indicates that there is a strong correlation between these two variables.

Table VII: Pearson correlation between $\mathrm{h}$-index and i10-index

\begin{tabular}{|ll|r|r|}
\hline & & h-index & i10-index \\
\hline \multirow{4}{*}{ H-index } & Pearson Correlation & 1 & $.932^{* *}$ \\
& Sig. (2-tailed) & & .000 \\
& $\mathrm{~N}$ & 45 & 45 \\
& Pearson Correlation & $.932^{* *}$ & 1 \\
i10-index & Sig. (2-tailed) & .000 & \\
& $\mathrm{~N}$ & 45 & 45 \\
\hline
\end{tabular}

**. Correlation is significant at the 0.01 level (2-tailed). 


\section{Discussion}

This research has examined the profiles of Pakistani LIS scholars who were members of the Google Scholar Citations profiling platform as of late 2017/early 2018.

In general, as would be expected, demographics for this group were similar to the authors' (Anonymous, 2017) survey of ResearchGate, especially the distribution by sector affiliation. The ratio of public institutions to private (53.33: 46.67) was close to that of 2017 (57.69: 42.31). The ratio of male to female was noticeably higher (84.44: 15.56) than in 2017 (73.08: 26.92). The distribution by gender shows the dominance of males, as corroborated by a number of recent Pakistani library studies (Ali and Richardson, 2016; Khan and Ahmed, 2013; Arif and Mahmood, 2012; Naseer and Mahmood, 2009). The study by Jan and Anwar (2013) did not report on either sector affiliation or gender.

As with the authors' 2017 study, the distribution by geographical region in the current study continued to show the predominance of two provinces (Punjab, 62.22 per cent and Federal capital, 17.78 per cent), followed by KPK (11.11 per cent) and Sindh ( 8.89 percent). The high figures for the Punjab region may reflect the relatively strong metrics in Google Scholar for faculty members at the University of the Punjab (Jan and Anwar, 2013).

Although Jan and Anwar (2013) did not draw any conclusions from their data, they did report on the extent of collaboration with other authors. Their six top performing faculty members, in terms of numbers of publications and citations, had collaborated with 82 other LIS scholars to produce 111 publications. Of these 82, 20 (or 24.39 per cent) were international authors. While the current study did not collect this type of data, the authors did note that the top performing scholar, in terms of Google Scholar Citations metrics, had co-authored publications with 29 other LIS scholars, who also had profiles in Google Scholar. Seven (or 24.13 per cent) of the 20 scholars are currently located outside of Pakistan.

A number of studies have highlighted the positive benefits of collaborative authorship. Ardanuy (2012, pp. 887-888), for example, found that:

The number of citations of papers with multiple authors is on average independent of the number of authors, oscillating between 3.7 and 3.9 but higher than that for those signed by a single author (2.22). That is to say, the impact of papers published in collaboration is greater, although this does not appear to be subject to significant changes if the collaborative work involves fewer authors or more. The only difference is between publishing alone or in collaboration.

Schoombee and du Plessis (2013) have provided a substantive overview of the benefits of collaboration, including a demonstrated relationship between multi-authorship and total publications.

Although studies have reported the level of multi-authorship in Pakistani LIS publications, including international percentages, their respective discussions have tended to focus more on the desirability of increasing research impact through publishing in impact factor (IF) journals. While acknowledging this as a valid point, the authors of the current study would suggest that a starting point for achieving that goal would in fact be to seek other scholars with whom to collaborate. 
$R Q$ 1. How many Pakistani LIS scholars, identified previously in a 2017 study, have a Google Scholar Citations profile?

The authors' current study revealed that only a moderate number of LIS scholars had a GS profile $(45$, or 57.69 per cent). In addition, there was a very high percentage of practitioners represented (71.12) as compared with faculty members (28.88); the latter accounted for 29.46 per cent in the authors' 2017 study. The statistics for faculty members provide some useful points of comparison with the results reported by Jan and Anwar (2013). Their study found that 11 of 53 LIS faculty members across eight Pakistani universities had at least one publication with a citation in Google Scholar; these 11 faculty members represented 6 universities. The authors found that, as of early 2018, there were eleven Pakistani higher education institutions with LIS faculty, of which only 5 institutions were represented in Google Scholar with a total of 13 faculty members. Clearly, there has not been a marked increase over the past seven years in Google Scholar Citations profiles for Pakistani LIS faculty members. In fact, the overall uptake remains quite low.

RQ 2. How well has this cohort performed in terms of Google Scholar Citations metrics, i.e. number of publications, citations, h-index score, and i10-index score?

Three scholars (6.67 per cent) accounted for 354 (41.26 per cent) of the total number (858) of publications in Google Scholar for this cohort. As mentioned previously, these three scholars were considered as outliers; they also were, not surprisingly, faculty members. In their survey specifically of LIS faculty, Jan and Anwar (2013) reported that three staff accounted for 80.51 per cent of the 118 publications. Of these three academics, two were also represented in the authors' current survey.

858 publications received 4,653 citations. As shown in Table III, the publications of 20 percent (9) of the total number of scholars accounted for 3,738 citations, i.e. 80 per cent of total citations. Jan and Anwar (2013, p. 10) reported similar results, thus observing that "It looks like the $80 / 20$ rule applies". Known as the Pareto Principle, it has been reported in similar studies (Yang and Wang, 2015; Gan and Wang, 2014).

A high percentage of scholars (88.89 per cent) had a Google Scholar h-index score. Despite the strong association between the number of citations and corresponding h-index among this cohort, the authors found that, in general, h-index scores tended to range between 1 and 5 (refer Figure 2). In their study, Jan and Anwar (2013) reported that the top six faculty members in their study had an h-index score that ranged between 2 and 9 . They further concluded that these scores were well below those reported by Cronin and Meho (2006, p. 1277) for information scientists in the US. The latter group had scores between 5 and 20 .

In his study of influential British LIS researchers, Oppenheim (2007, p. 300) concluded that when using Hirsch's h-index, "the target $h$-index score for a LIS researcher to be considered "successful" is about 5 and to be considered "highly successful" is about 13". For its part, in a later study of social science researchers in the UK, the LSE Public Policy Group (2011, p. 87) found that social science academics tended to have markedly lower average (Hirsch's) h-index scores than did science academics, e.g. 2.8 in law. In addition, they found that in the social sciences, the range of $h$-scores that are attained by staff at different levels of age and seniority are markedly different (p. 86). 
The principal challenge with benchmarking Pakistani LIS scholars against the studies by Cronin and Meho (2006) and Oppenheim (2007) is twofold: scale and comparability. First, given the proportionately larger overall number of LIS researchers in both the US and the UK, these two studies have focused on a specific sub-set, i.e. the more active and influential (top ranking) members within this cohort, rather than on the sector as a whole. Second, the basis for the metrics reported in the two international studies was Web of Science data, i.e. impact factor (IF) journals. As discussed above, applying this same approach to Pakistani LIS scholars simply reinforces an already known issue, i.e. this cohort has a low record of publishing in IF journals.

Finally, nearly 60 per cent of scholars in the authors' study had an i10-index score, which indicates that the majority of this cohort has published at least one scholarly output that has a double-digit citation score. While unique to Google Scholar Citations, this score is useful for helping to identify a scholar's most highly cited papers in contrast with the breadth of their impact (h-index). The authors have found no study that has reported on the application of Google Scholar's h i10--index to specific cohorts of scholars.

\section{$R Q$ 3. What is the correlation (if any) among Google Scholar Citations metrics?}

Pearson correlation results showed that there were strong correlations between the traditional metrics used by Google Scholar Citations (publications, citations, and h-index) as well as with its unique i10index. These results are in line with the study by Harzing and Van der Wal (2008), which compared Google Scholar with other major citation databases.

RQ 4. What activities could LIS scholars and other stakeholders undertake to leverage the potential of Google Scholar Citations' profiling system?

As the authors have indicated in the introduction to their literature review, their intention is not to focus on traditional citation databases as the only vehicle for measuring the impact of LIS scholars in Pakistan. Ali and Richardson (2016) and Jan and Anwar (2013) have noted that most of the outputs authored by this cohort are published in journals not indexed by either WoS or Scopus, which thereby decreases the potential for increased citation counts in major commercial databases. Furthermore, Ali and Richardson (2016) reported that there was only one Pakistani LIS journal represented in Scimago's Journal and Country Rankings, the Pakistan Journal of Information Management and Libraries, which as of 2014 had a citation rate of 0.17 and ranked 179 out of the 199 worldwide LIS titles listed in the Scimago database. As of 2017, it had a citation rate of 0.14 and ranked 163 out of 226 LIS titles (https://www.scimagojr.com/).

For this reason, the profiling platforms offered by several of the major ASNS provide an alternative for showcasing one's research outputs. They include research content not generally indexed by the commercial databases, thereby providing a mechanism by which authors can list, for example, articles that have been published in print journals.

Google Scholar Citations' profiling platform, specifically, is an attractive option for several reasons. First, it offers quite a wide breadth of coverage in terms of content types (Delgado López-Cózar et al., 2018). Second, Kousha and Thelwall (2017, p. 763) have noted its usefulness for "scholarly publications in languages and countries that are not well covered by WoS or Scopus". Third, creating a profile is free (Kim, 2014). Harzing and Van der Wal (2008, p. 61) refer to the "democratization" of citation analysis for 
authors without access to subscription-based citation indices. Wimmer at al. (2016, p. 406) concur and mention, in addition, its usefulness for "authors with a multidisciplinary focus or those in disciplines publishing outside of traditional journal literature". These aspects are important factors for those developing countries, such as Pakistan, that have implemented strategic goals about improving their national research profile.

The authors' premise is that Pakistani LIS scholars should examine the potential of this profiling platform to improve their visibility as a researcher. Because the primary focus is on a scholar's visibility rather than performance evaluation, the issues acknowledged above regarding duplicate records and selfcitations should not be deterrents to creating an online profile. Through their researcher profile, scholars can leverage their improved visibility to find potential new audiences and collaborators (Ali et al. 2017; Ale Ebrahim et al., 2014).

While a researcher may wish to improve their research impact through higher bibliometric scores, e.g. $\mathrm{h}$-index, they need to lay the foundation to achieve this strategic goal. Given their current key role in supporting the research lifecycle, libraries are a significant resource. In addition to the strategies suggested by Schoombee and du Plessis (2013) for libraries to help facilitate collaboration among researchers, librarians have an important role in advising on best practice in post-publication strategies, including creating an effective academic profile. For example, as Ali et al. (2017, p. 736) have observed, "Advising authors regarding copyright and licensing is as important when applied to ASNS as it is when initially selecting a publication outlet".

This approach need not be limited to just developing countries, such as Pakistan. The University of New South Wales, an Australian research-intensive university, has announced its goal of becoming a top 50 university by 2025 in the major international ranking systems. The Deputy Vice-Chancellor (Research) has identified six strategies to achieve this goal, including creating a Google Scholar page (i.e. Google Scholars Citation profile) and seeking expert advice on building a research profile (Matchett, 2018).

\section{Limitations}

This study of Google Scholar Citations is limited to those Pakistani LIS scholars who already had a profile in ResearchGate. Scholars could gain valuable insights by broadening future research to encompass all Pakistani LIS scholars as well as those in other disciplines, particularly in the social sciences.

\section{Conclusion}

With the increased worldwide focus on enhancing the visibility and impact of research, scholars are exploring new means of communicating their research outputs, including scholarly online profiling systems.

Building on a previous study (Anonymous, 2017), the authors have reported on the use of Google Scholar Citations' profiling platform by LIS scholars in Pakistan. Their research has shown that while the uptake has continued to be relatively low, the platform offers a potentially useful tool that addresses some of the issues currently faced by this cohort, including publishing in languages and/or journals that are not indexed by traditional citation databases. Furthermore, as advisers in scholarly communication and impact, the role of academic librarians can be extended to support scholars in the adoption of new online platforms for communication and visibility. 


\section{References}

Abbasi, A., Altmann, J. and Hossain, L. (2011), "Identifying the effects of co-authorship networks on the performance of scholars: a correlation and regression analysis of performance measures and social network analysis measures", Journal of Informetrics, Vol. 5 No. 4, pp. 594-607.

Ale Ebrahim, N., Salehi, H., Embi, M.A., Habibi, F., Gholizadeh, H. and Motahar, S.M. (2014)," Visibility and citation impact", International Education Studies, Vol. 7, No. 4, pp. 120-125.

Ali, M.Y. and Richardson, J. (2016), "Research publishing by library and information science scholars in Pakistan: a bibliometric analysis", Journal of Information Science Theory and Practice, Vol. 4 No. 1, pp. 620.

Ali, M.Y. and Richardson, J. (2018), "Usage of academic social networking sites by Karachi social science faculty: implications for academic libraries", IFLA Journal, Vol. 44 No. 1, pp. 23-34.

Ali, M.Y., Wolski, M. and Richardson, J. (2017) "Strategies for using ResearchGate to improve institutional research outcomes", Library Review, Vol. 66 No. 8/9, pp.726-739,

Anonymous (2017). [Citation details removed for purposes of anonymity].

Ardanuy, J. (2012), "Scientific collaboration in library and information science viewed through the Web of Knowledge: the Spanish case", Scientometrics, Vol. 90 No. 3, pp. 877-890.

Arif, M. and Mahmood, K. (2012), "The changing role of librarians in the digital world: adoption of Web 2.0 technologies by Pakistani librarians", The Electronic Library, Vol. 30 No. 4, pp. 469-479.

Beel, J. and Gipp, B. (2009), "Google Scholar's ranking algorithm: the impact of articles' age (an empirical study)", in Latifi, S. (Ed), Proceedings of the 2009 Sixth International Conference on Information Technology: New Generations, IEEE, Los Alamitos, CA, pp. 160-164, available at: https://doi.org/10.1109/itng.2009.317 (accessed 11 July 2018).

Bornmann, L. (2014), "Do altmetrics point to the broader impact of research? An overview of benefits and disadvantages of altmetrics", Journal of informetrics, Vol. 8 No. 4, pp. 895-903.

Bornmann, L., Thor, A., Marx, W. and Schier, H. (2016), "The application of bibliometrics to research evaluation in the humanities and social sciences: an exploratory study using normalized Google Scholar data for the publications of a research institute", Journal of the Association for Information Science and Technology, Vol. 67 No. 11, pp. 2778-2789.

Cronin, B. and Meho, L. (2006), "Using the h-index to rank influential information scientists", Journal of the Association for Information Science and Technology, Vol. 57 No. 9, pp. 1275-1278.

Delgado López-Cózar, E., Orduna-Malea, E. and Martín-Martín, A. (2018), "Google Scholar as a data source for research assessment", arXiv preprint, arXiv:1806.04435, available at: https://arxiv.org/abs/1806.04435 (accessed 11 July 2018).

Delgado López-Cózar, E., Robinson-García, N. and Torres-Salinas, D. (2014), "The Google Scholar experiment: how to index false papers and manipulate bibliometric indicators", Journal of the Association for Information Science and Technology, Vol. 65 No. 3, pp. 446-454.

DeSanto, D. and Nichols, A. (2017, "Scholarly metrics baseline: a survey of faculty knowledge, use, and opinion about scholarly metrics", College \& Research Libraries, Vol. 78 No. 2, pp. 150-170.

Doğan, G., Şencan, I. and Tonta, Y. (2016), "Does dirty data affect Google Scholar Citations?", Proceedings of the Association for Information Science and Technology, Vol. 53 No. 1, pp. 1-4. 
Falagas, M.E., Pitsouni, E.I., Malietzis, G.A. and Pappas, G. (2008), “Comparison of PubMed, Scopus, Web of Science, and Google Scholar: strengths and weaknesses", The FASEB Journal, Vol. 22 No. 2, pp. 338342.

Gan, C. and Wang, W. (2014), "A bibliometric analysis of social media research from the perspective of library and information science", in Li, H., Mäntymäki, M. and Zhang, X. (Eds), Digital Services and Information Intelligence, Springer, Berlin, pp. 23-32, available at: https://doi.org/10.1007/978-3-66245526-5_3 (accessed 11 July 2018).

Gasparyan, A.Y., Nurmashev, B., Yessirkepov, M., Endovitskiy, D.A., Voronov, A.A. and Kitas, G.D. (2017), "Researcher and author profiles: opportunities, advantages, and limitations", Journal of Korean Medical Science, Vol. 32 No. 11, pp. 1749-1756.

Gingras, Y. (2016), Bibliometrics and Research Evaluation: Uses and Abuses, MIT Press, Cambridge, MA. Hartman, K.A. and Bowering Mullen, L. (2008), "Google Scholar and academic libraries: an update", New Library World, Vol. 109 No. 5/6, pp. 211-222.

Hammarfelt, B.M.S., Rijcke, S.D. and Rushforth, A.D. (2016), “Quantified academic selves: the gamification of science through social networking services", Information Research, Vol. 21 No. 2, paper SM1, [HTML only, no pagination], available at: http://www.informationr.net/ir/21-2/SM1.html (accessed 11 July 2018).

Harzing, A.W.K. and van der Wal, R. (2008), "Google Scholar as a new source for citation analysis", Ethics in Science and Environmental Politics, Vol. 8 No. 1, pp. 61-73, available at: https://doi.org/10.3354/esep00076 (accessed 11 July 2018).

Hirsch, J.E. (2005), "An index to quantify an individual's scientific research output", Proceedings of the National Academy of Sciences of the United States of America, Vol. 102 No. 46, pp. 16569-16572.

Jacsó, P. (2012), "Google Scholar author citation tracker: is it too little, too late?", Online Information Review, Vol. 36 No. 1, pp. 126-141.

Jan, S.U. and Anwar, M.A. (2013), "Impact of Pakistani authors in the GOOGLE world: a study of library and information science faculty", Library Philosophy and Practice, Summer, article no. 980, pp. 1-18, available at: https://digitalcommons.unl.edu/libphilprac/980/ (accessed 11 July 2018).

Jordan, K. and Weller, M. (2018), "Academics and social networking sites: benefits, problems and tensions in professional engagement with online networking", Journal of Interactive Media in Education, Vol. 2018 No. 1, pp. 1-9, available at: http://doi.org/10.5334/jime.448 (accessed 11 July 2018).

Karanatsiou, D., Misirlis, N. and Vlachopoulou, M. (2017), "Bibliometrics and altmetrics literature review: performance indicators and comparison analysis", Performance Measurement and Metrics, Vol. 18 No. 1, pp. 16-27.

Khan, A. and Ahmed, D. (2013), "Job satisfaction among librarians in the universities of Khyber Pakhtunkhwa, Pakistan: a survey", Library Philosophy and Practice, December, article no. 906, pp. 1-12, available at: https://digitalcommons.unl.edu/libphilprac/906/ (accessed 11 July 2018).

Kim, H. (2014), "An investigation of information usefulness of Google Scholar in comparison with Web of Science", 한국비블리아학회지 (Journal of the Korean BIBLIA Society for library and Information Science), Vol. 25 No. 3, pp. 215-234, available at: http://www.dbpia.co.kr/Journal/ArticleDetail/NODE02479161 (accessed 11 July 2018) 
Kousha, K. and Thelwall, M. (2017), "Are Wikipedia citations important evidence of the impact of scholarly articles and books?", Journal of the Association for Information Science and Technology, Vol. 68 No. 3, pp. 762-779.

LSE Public Policy Group (2011), Maximizing the Impacts of Your Research: A Handbook for Social Scientists. London School of Economics, London, available at:

https://www.american.edu/provost/grad/upload/LSE_Impact_Handbook_April_2011.pdf (accessed 11 July 2018).

Martín-Martín, A., Orduña-Malea, E., Ayllón, J.M. and López-Cózar, E.D. (2016), “The counting house: measuring those who count: presence of bibliometrics, scientometrics, informetrics, webometrics and altmetrics in the Google Scholar Citations, ResearcherID, ResearchGate, Mendeley \& Twitter", arXiv preprint, arXiv:1602.02412, available at: https://arxiv.org/abs/1602.02412 (accessed 11 July 2018).

Martín-Martín, A., Orduna-Malea, E. and López-Cózar, E.D. (2018), "Author-level metrics in the new academic profile platforms: the online behaviour of the bibliometrics community", Journal of Informetrics, Vol. 12 No. 2, pp. 494-509

Matchett, S. (2018), "UNSW pays for performance”, Campus Morning Mail, 13 July, available at: https://campusmorningmail.com.au/news/unsw-pays-for-performance/ (accessed 18 July 2018)

Meho, L.I. and Yang, K. (2007), "Impact of data sources on citation counts and rankings of LIS faculty: Web of Science versus Scopus and Google Scholar", Journal of the American Society for Information Science and Technology, Vol. 58 No. 13, pp. 2105-2125.

Mingers, J. and Lipitakis, E. (2010), "Counting the citations: A comparison of Web of Science and Google Scholar in the field of business and management", Scientometrics, Vol. 85, No. 2, pp. 613-625.

Mingers, J. and Meyer, M. (2017, "Normalizing Google Scholar data for use in research evaluation", Scientometrics, Vol. 112 No. 2, pp. 1111-1121.

Moed, H.F., Burger, W.J.M., Frankfort, J.G. and Van Raan, A.F. (1985), "The use of bibliometric data for the measurement of university research performance", Research Policy, Vol. 14 No. 3, pp. 131-149

Naseer, M.M. and Mahmood, K. (2009), "LIS research in Pakistan: an analysis of Pakistan Library and Information Science Journal 1998-2007", Library Philosophy and Practice, June, pp. 1-10, available at: http://hdl.handle.net/10760/13803 (accessed 11 July 2018).

Naude, F, (2017). "Comparing downloads, Mendeley readership and Google Scholar citations as indicators of article performance", The Electronic Journal of Information Systems in Developing Countries, Vol. 78 No. 1, pp. 1-25. [Note: Wiley has issue no. $=4$ on the PDF]

Office of Economic Development (2010). Enhancing Research Performance through Evaluation, Impact Assessment and Priority Setting, OECD Publishing, Paris, available at: https://www.oecd.org/sti/inno/Enhancing-Public-Research-Performance.pdf (accessed 10 July 2018).

Oppenheim, C. (2007), "Using the h-index to rank influential British researchers in information science and librarianship", Journal of the Association for Information Science and Technology, Vol. 58 No. 2, pp. 297-301.

Oravec, J.A. (2017), "The manipulation of scholarly rating and measurement systems: constructing excellence in an era of academic stardom", Teaching in Higher Education, Vol. 22 No. 4, pp. 423-436.

Orduna-Malea, E., Martín-Martín, A. and Delgado López-Cózar, E. (2016), “Metrics in academic profiles: a new addictive game for researchers?", Revista Española de Salud Pública, Vol. 90 No 22 Sept, pp. e1-5, available at: 
http://www.msssi.gob.es/biblioPublic/publicaciones/recursos_propios/resp/revista_cdrom/VOL90/C_ES PECIALES/RS90C_EDLCingles.pdf (accessed 11 July 2018).

Ortega, J.L. and Aguillo, I.F. (2012). "Science is all in the eye of the beholder: keyword maps in Google Scholar Citations", Journal of the American Society for Information Science and Technology, Vol. 63, No. 12, pp. 2370-2377.

Ortega, J.L. and Aguillo, I.F. (2014), "Microsoft Academic Search and Google Scholar Citations: comparative analysis of author profiles", Journal of the Association for Information Science and Technology, Vol. 65, No. 6, pp. 1149-1156.

Priem, J., Piwowar, H. A. and Hemminger, B. M. (2012), "Altmetrics in the wild: using social media to explore scholarly impact", arXiv preprint, arXiv:1203.4745, available at: https://arxiv.org/abs/1203.4745 (accessed 11 July 2018).

Schoombee, L. and du Plessis, P. (2013), "Making the link: the library's role in facilitating research collaboration", 2013 IATUL Proceedings, paper 53, pp. 1-16, available at: http://docs.lib.purdue.edu/iatul/2013/papers/53 (accessed 10 July 2018).

Shah, S.R.U., Mahmood, K. and Hameed, A. (2017), "Review of Google Scholar, Web of Science, and Scopus search results: the case of inclusive education research", Library Philosophy and Practice, Spring, pp. 1-11, available at: https://digitalcommons.unl.edu/libphilprac/1544/ (accessed 11 July 2018).

Sheikh, A. (2016), "Awareness and use of academic social networking websites by the faculty of CIIT", Qualitative \& Quantitative Methods in Libraries, Vol. 5 No. 1, pp. 177-188.

Tashakkori, A. and Teddlie, C. (Eds.), (2003). Handbook of Mixed Methods in Social \& Behavioral Research, Sage, Thousand Oaks, CA

Thelwall, M. and Kousha, K. (2015), "Web in indicators for research evaluation. Part I: Citations and links to academic article from the web", El Profesional de la Información, Vol. 24 No. 5, pp. 587-606.

Thelwall, M. and Kousha, K. (2017), "ResearchGate versus Google Scholar: which finds more early citations?”, Scientometrics, Vol. 112, No. 2, pp. 1125-1131.

Van Bevern, R., Komusiewicz, C., Niedermeier, R., Sorge, M. and Walsh, T. (2015), "H-index manipulation by merging articles: models, theory, and experiments", in Yang, Q. and Wooldridge. M. (Eds), Proceedings of the Twenty-Fourth International Joint Conference on Artificial Intelligence, 25-31 July, Buenos Aires, pp. 808-814, available at: http://ijcai.org/Proceedings/15/Papers/119.pdf (accessed 11 July 2018).

Van Bevern, R., Komusiewicz, C., Niedermeier, R., Sorge, M. and Walsh, T. (2016), "H-index manipulation by merging articles: models, theory, and experiments", Artificial Intelligence, Vol. 240 [no issue number], pp. 19-35.

Veletsianos, G. (2016), Social Media in Academia: Networked Scholars, Routledge, New York.

Vine, R. (2006), "Google Scholar", Journal of the Medical Library Association, Vol. 94 No. 1, p. 97.

Wildgaard, L., Schneider, J.W. and Larsen, B. (2014), "A review of the characteristics of 108 author-level bibliometric indicators," Scientometrics, Vol. 101 No. 1, pp. 125-158.

Williams, A.E. and Woodacre, M.A. (2016), "The possibilities and perils of academic social networking sites", Online Information Review, Vol. 40 No. 2, pp. 282-294 
Wimmer, E.N., Rethlefsen, M.L., Jarvis, C. and Shipman, J.P. (2016), "Understanding research impact: a review of existing and emerging tools for nursing", Journal of Professional Nursing, Vol. 32 No. 6, pp. 401-411.

Yang, K. and Meho, L.I. (2006), "Citation analysis: a comparison of Google Scholar, Scopus, and Web of Science", Proceedings of the American Society of Information Science and Technology, Vol. 43 No. 1, pp. 1- 15, available at: https://doi.org/10.1002/meet.14504301185 (accessed 11 July 2018).

Yang, S. and Wang, F. (2015), "Visualizing information science: author direct citation analysis in China and around the world", Journal of Informetrics, Vol. 9 No. 1, pp. 208-225.

Yu, M. C., Wu, Y. C. J., Alhalabi, W., Kao, H. Y. and Wu, W. H. (2016), "ResearchGate: An effective altmetric indicator for active researchers?", Computers in Human Behavior, Vol. 55 Part B, pp. 10011006 